\title{
Research on the Construction of Biological Laboratory Management Mode in Colleges at the New Era
}

\author{
Shiying Wang \\ Aba Teachers University, Aba, Sichuan, 623002
}

Keywords: Biological Laboratory, Management Model, New Era

\begin{abstract}
University laboratory is an important educational platform for personnel training, which plays an important role in consolidating students 'theoretical knowledge, improving students' practical ability and improving teaching quality. Now, under the environment of putting emphasis on quality education, the proportion of experimental teaching in college education teaching is increasing. University laboratory management is an indispensable and important part in college management. Therefore, in the new period, study how to strengthen the university laboratory management, provide a good experimental class environment for the majority of teachers and students is an important issue which college administrators need to seriously deal with.
\end{abstract}

\section{Introduction}

Biological science is a natural science based on the experiment, only with a solid theoretical basis of scientific experiments in order to better engage in scientific research. "Scientific research and social service is the three major functional objectives of colleges and universities. Scientific research is an important way to cultivate talents in colleges and universities. Therefore, the laboratory is an important place for cultivating talents in colleges and universities. With the rapid development of life science in the 21st century, Biological laboratory construction and management has brought unprecedented opportunities and challenges. College of Biology Laboratory Management is an important part of the management of biological laboratory in colleges and universities. With the continuous expansion of the scale of biological laboratory, the construction of laboratory there are many management loopholes in the management mode of the biology teaching laboratory of the university. The laboratory management system is not perfect, the laboratory management system is imperfect, the order of the teaching laboratory is chaotic, no one is willing to manage, there are many types of equipment and loss the scientific management and maximizing the utilization of teaching laboratories have become an important subject in the development of colleges and universities. Therefore, it is necessary to improve the quality of the laboratory.

\section{The Current Status of Laboratory Management in Colleges}

The major colleges and universities are affected by the current laboratory management system, leading to the internal laboratories are usually in a separate and independent management of the state, the lack of effective between the various laboratory horizontal contact, making the laboratory management the center is often confined to their own authority, and can not be a comprehensive management of the various laboratory coordination and integration. In a sense, the university's laboratory is mainly for the teachers and students of the daily teaching activities and related research work to provide services, so usually the relevant information in the laboratory will not be published, which led to other outside the demand for the lack of understanding of the laboratory of colleges and universities, thus hindering the effective functioning of the laboratory.

For the construction and development of colleges and universities, the lack of education funding has always been the impact and impact the pace of development of an important factor. Due to the impact of education funding constraints, resulting in the major colleges and universities in the layers of the deployment of education funding, can be allocated to the laboratory construction costs are limited, coupled with the dramatic increase in the number of students, resulting in college students per capita experiment room resources without increasing the anti-down, at the same time, 
the closed state of the various laboratories, making the laboratory between the interrelated and communication are relatively lacking, resulting in limited college experimental funding is often put into the laboratory to repeat the construction, which makes many of the low-end equipment is a lot of idle, and high-end equipment has been unable to buy. In short, the impact of the constraints received by the construction of the laboratory, it will inevitably lead to a large extent in the laboratory related equipment and equipment aging phenomenon, and not timely update and maintenance, in such a teaching environment, the actual ability of students will be seriously affected and limited.

As the teaching of colleges and universities has long been affected by the traditional educational philosophy and constraints, resulting in the actual teaching process often there will be a clear light experiment, heavy theoretical phenomenon. With the arrival and development of Chinese knowledge economy era, more and more colleges and universities have begun to realize the importance of experimental teaching in the process of personnel training, and have also effectively strengthened the experimental teaching. However, in view of the actual teaching situation, the subject position of the experimental teaching in colleges and universities still has not been clearly identified, which has been in a state of subordinate status, which makes the teaching process enthusiasm is not high, and therefore serious the influence of students in the experimental teaching of learning enthusiasm, coupled with some colleges and universities are still using the traditional teaching methods and methods of teaching activities, making the experimental teaching quality and efficiency has also been seriously affected.

In short, the quality of the level of laboratory personnel and skills, often can directly determine the school laboratory teaching and related research level. However, the current actual situation, because the major colleges and universities in the laboratory for a long time not receive effective attention, resulting in the staff in the laboratory also appeared in the obvious loopholes, for the evaluation of the title of the laboratory staff and evaluation awards and other aspects of the work, often showing a low and low proportion of the state. Because of the limited space and rising channels of staff in the laboratory, coupled with lower working conditions and lower pay for laboratories, laboratory construction is often in a state of lag, with many talents for experimentation The work of the room is biased, and do not want to work in the laboratory environment, in such circumstances, the laboratory is often only the daily teaching management, for many sophisticated equipment R \& D and research projects carried out are lacking.

\section{Research on the Management Mode of Biological Laboratory in Colleges}

The management of the laboratory should be meticulous and meticulous, and adopt quantitative management and incentive competition system so as to lay a solid foundation for the smooth development of teaching and scientific research in colleges and universities. To this end, the laboratory should first gradually improve the management system, the experimental sites, technical personnel, equipment and work tasks and other information archives and orderly standardized management, so that the laboratory rules to follow, the establishment of rules and regulations of the laboratory equipment maintenance, maintenance and damage repair and other issues of the solution, the best professional staff management, implementation of the training system; Finally, a clear responsibility system, division of the experimental teachers, labors and leaders of their respective responsibilities scope, the establishment of a series of related supporting management system, such as rewards and punishments, etc., it is best to be specific issues to determine the responsible person.

To teachers' own thinking as a starting point, and actively expand the students' thinking, attention to the cultivation of students' innovative ability. Experimental teachers not only need to engage in scientific research and experimental construction, but also the direct participation of experimental teaching, the quality of their work will be the level of scientific research and teaching quality have a direct impact on the construction and training of talent important issues.

In order to improve the professional quality of the laboratory staff, the school should actively arrange the relevant staff of the relevant training work, and constantly improve their academic and experimental business level. For the management of the faculties, it is important to recognize the 
importance of the experimental staff's love of their jobs and to pay close attention to the proportion of the outstanding staff in the year-end appraisal and the relevant technical titles, and to appropriately raise their salary.

In the work, the experimental teacher should be with the administrator, technician in a timely manner, in close cooperation, play a spirit of unity and cooperation, love work and fail to shirk responsibility. It can establish a hierarchical management system and the preparation of laboratory staff can be managed by the department, as far as possible to achieve comprehensive utilization of human resources and the advantages of portfolio. The new staff to take the trial, equipment maintenance interview program, strict management system, the work of dereliction of duty, the occurrence of major laboratory safety accidents and teaching accidents to reduce the allowance and dismissal and other severe punishment.

As the experimental teachers and labors are the actual managers of biological laboratories, so they are not only have a strong professional level, while the whole set of experimental equipment is responsible for, with a certain concentration of study spirit, so in the face of difficult or ineffective Ideally, they can be improved in a timely manner. Of course, the experimental teacher should also be both ability and political integrity, so as to ensure that the experimental results to a high standard. On the other hand, the school should also strive to improve and improve the teacher's title assessment, promotion and welfare levels, to lift their worries, so that they put more enthusiasm into the experimental teaching management.

The file construction of the equipment is an important guarantee for the smooth development of the scientific research and teaching work. Therefore, the departments should strive to improve their utilization rate and give full play to their economic benefits while ensuring the integrity of the experimental instruments.

From the project declaration, assembly and unpacking the three basic work to start the box to carry out the equipment and equipment management work. At the same time should do a good job in advance with technical information and instructions complete, the host inspection and attachment configuration is correct and so check the record work.

The establishment of technical file system is from the equipment selection, acquisition, demonstration, use, acceptance, commissioning and the maintenance to the full technical management of the scrapped. Precious instruments and technical archives should be a true record of the process from the purchase of an instrument to its scrapping, and this valuable information will undoubtedly affect the cost-effectiveness of the instrument, the experimental benefits and the level of management of the technical staff and the level of business the assessment has a very important role.

In order to better realize the preservation of equipment and technical files, instrument management and value management should be combined. Experimental equipment managers should not only optimize management, but also efforts to improve the level of operational skills and standard standards, so that regular inspection and scientific management and gives full play to the role of instrument files. It is proposed to gradually adopt the electronic computer network management to realize the transition from paper documents to paperless documents, and to a certain extent, with the help of network technology to expand the amount of information and services.

\section{Conclusion}

With the continuous development of harmonious socialist society, the management of biology teaching laboratory in colleges and universities occupies an important position in the laboratory management of colleges and universities. Building a harmonious laboratory is the responsibility and obligation of each laboratory staff. As a university biological laboratory manager, they have the responsibility to analyze and summarize university biology teaching laboratory management seriously from the reality and continuously improve the efficiency. 


\section{References}

[1] Sui Beibei, Han Aizhong. The university biological laboratory culture construction[J]. Higher Education Journal, 2015 (18)

[2] Deng Fang. College of biological laboratory management of some experience[J]. Shenzhou. $2014(05)$

[3] You Jihong. Create green biological laboratory [J]. Experimental Science and Technology, 2014 (02)

[4] Wang Xiaolin. Discussion on the management of research-based biological laboratory[J]. Chinese out-of-school education, 2012 (31)

[5] Sun Yan. Green, safe and environmentally friendly biological laboratory construction and management[J]. Time Education, 2015 (01)

[6] Huo Xinlu. Development direction of biological laboratory in local normal universities[J]. Journal of Experimental Science and Technology, 2012 (05) 